etry are proved logically from the axioms is proclaimed most vociferously, that we find such fallacious proofs given the utmost prominence. Is it not evident that no theorem can possibly be proved about the areas of circles in a book in which no definition of area is given which in any sense applies to a circle? Nor is reference made to any special text. These fallacies have become traditional, so that many an author has inserted them without real forethought.

I will lastly call attention to the fact that all the theorems on similar triangles involve these same questions, and that these theorems cannot be proved unless the approximation in the very defininition of areas is recognized.

(To be continued.)

\title{
THE TEACHING OF GEOMETRY IN ITS RELATION TO THE PRESENT EDUCATIONAL TREND.*
}

\author{
By William Betz,
}

East High School, Rochester, N. Y.

Existence of a Reform Movement. A few months ago the principal of a well known school said to me, "The teaching of geometry has become stale. Something must be done to put new life into it." This remark struck the very keynote of the present reform movement. That one has a right to speak of a reform movement in the teaching of mathematics, must be evident to any but a very indifferent observer. The agitation in favor of better teaching is not confined to our own country, and its effects are felt in colleges, universities, secondary and primary schools, with almost equal force. It is unnecessary to recite before an audience like this all the details of its origin and progress. Many of those here present could do that more impressively. It is sufficient to say that since Prof. E. H. Moore's nemorable address in December, I902, "On the Founclations of Mathematics," an ever increasing number of teachers have become actively interested in the pedagogy of mathematics. This is shown to be true by the large number of associations of teachers of mathematics and science organized within the past five years and by the numerous papers and reports published in that time.

* Read before the mathematics round table, National Education Association, Cleveland, July 2,1908 . 
A vigorous battle has been going on between the radical and conservative schools, between individualism and dogmatism. By this time the smoke of battle has cleared away sufficiently to warrant a diagnosis of the case and perhaps a prognosis.

It is my pleasant duty this afternoon to attempt a brief discussion of the geometry situation in our secondary schools, in the light of present educational tendencies.

Transforming Influences. At the very outset it is proper to ask, is there any real need of a reform movement? Aside from the general reason of progress in every department of human thought and activity, some four or five additional factors are contributing to the state of affairs we are now considering.

I. In the first place, modern industrialism, with its demand for tangible success, has led to a great outcry for more practical school work. There is an increasing contempt of "mere theory." This feeling finds its expression in the establishment of trade and technical schools such as this beatutiful city has the privilege of possessing. Geometry, as usually taught, furnishes a welcome target to the utilitarian educator. As a result there is a growing fear that we may drift too far from the ideal of liberal culture and that the direct bread-winning power of a subject may be made the sole criterion of its usefulness.

2. Our large cities, the natural centers of industry, are also becoming great centers of popitation. Naturally the struggle for existence is becoming keener. Many parents are now sending their children to the high school to fit them, in the briefest possible time, for a more comfortable life than they themselves enjoy. This has made the high school population more diversified than ever before and the demands imposed upon the schools have become more numerous from year to year. For the first time in history, secondary education is truly democratic. But it cannot be denied that the assimilation of so much raw material from homes giving no cultural impulses, and of so many stuclents having no intention of entering higher institutions of learning, is one of the most serious problems of the high school.

3. More far reaching than these changes of ideal and environment have been certain revolutions in school curricula and methods of instruction. The natural sciences have risen from comparative obscurity into great prominence. Their inductive method of investigation is considered by many as the great panacea for all our troubles. The influence of the laboratory 
method is undeniable. It is reacting, for example, on the teaching of history and the languages. In so far as it insists on selfreliance and definiteness of results and is productive of greater interest, it is excellent. But it lengthens school hours, calls for costly equipment, and demands much outside work on the part of pupil and teacher.

4. It would be difficult, moreover, to overestimate the effect of the "new education." Its fundamental precept that all work must be arranged psychologically and adapted strictly to the child's power of comprehension, is eminently sound. But it has also given us the enriched curriculum, and the doctrine of interest which replaces all objective standards by the subjective attitude of the child. Unquestionably this means at once a distinct advance and a very real source of danger. The complaint is not infrequent that in many cases the young are learning to depend too much upon the inspirational powers of the teacher, that all real difficulties are carefully avoided, and that the very aim of all true education, to develop a strong character and to create self-activity and initiative, is thereby defeated.

During the past five years we have heard much of the socia! function of the school. A prominent professor kindly informed us that until exercises in spelling, mental arithmetic and formal grammar should have become merely incidental and subsidiary, the high water mark in teaching would not have been reached. It is exaggerations of this sort that rob many otherwise excellent ideas of their legitimate influence and place upon them the stigma of the faddist.

5. Last, not least, I must refer to the molding power of recent research in the domain of pure mathematics. The labors of men like Pasch, Peano, Veronese, Hilbert, Klein, Russell, and others are making it clear that the subject of rigor in geometry is one of extreme delicacy. It appears that our text-books are full of hidden assumptions and that their usual boast of rigorous presentation is ludicrous.

Readjustments. Standing in the very midst of this whirlpool of conflicting forces and tendencies the conscientious teacher of mathematics feels vaguely, though instinctively, that his subject is in need of repair. His feeling is one of unenviable uncertainty. The new situation makes great demands on his training. He does not know how to steer clear of Scylla and Charybdis, how to modernize and revitalize his subject in the 
face of the many obstacles that beset his way, not the least of which is represented by the inexorable requirements of examining boards. Is there any way out of the difficulty? As in all similar cases, a compromise would seem to be the natural outcone. Perhaps, by noting first the readjustments that have already taken place, we may secure a clearer vision of our future course. The old inflexible schedule of studies is giving way to a more liberal curriculum. This is a direct outgrowth of the doctrine of interest and of the new function of the high school as the people's university. Here also lies a great danger. Mathematics is one of the "hard" school subjects, and when it is placed in competition with easier and more attractive subjects, the pupil naturally follows the line of least resistance. As a college president happily phrased it, he abandons the Jerusalem of the calctulus for the Jericho of economics. It has become a witticism that water does not flow down hill so smoothly as the delighted student picks his way through a long list of electives. In this connection the following passage, taken from the third report of the Association of Mathematical Teachers in New England (Boston, I906), will be of interest: "That pupils and their parents are not awake to the importance of mathematics was shown conclusively by questions put to the principals of the Boston high schools in which the elective system is in force. In the English High and in the Roxbury High $25 \%$ of the entering class are taking no mathematics whatever. In the South Boston High $28 \%$ of the pupils have not made a year of algebra or geometry. In the Girls' High $53 \%$ of the first year pupils, in selecting their studies, chose no mathematics, 287 out of 544 girls; and in the East Boston High 165 out of 239 pupils in the entering class, or $69 \%$, are studying no mathematics."

Of far greater interest and importance are the efforts that have been progressing for some time to modify the compartment system in the teaching of mathematics, by which algebra is placed in the first year and geometry in the second. While he is studying geometry, the student promptly forgets his algebra, and during the third year he loses both algebra and geometry. Then, in the fourth year, we try to revive his interest by going over the same ground a second time. There is a great waste of energy in all this. I cannot regard the introduction of "non-preparatory" courses as a complete solution of this difficulty, even if such courses were possible in all schools. 
The various correlation and fusion plans advocated so far have not been tested sufficiently to warrant their general adoption. In Igo2, Professor E. H. Moore designated the unification of pure and applied mathematics as the fundamental problem. Mr. John C. Packard, a year later, predicted the formation of a new subject known as "everyday mathematics," by the fusion of physics, manual training, algebra and geometry. This constitutes the very heart of the Perry Movement. The practical realization of this scheme proved more difficult than was anticipated. So far as I know, it has been tried only in schools of unusual equipment, and even there has been only moderately successful. One impartial observer, after a careful inspection of the schools where this sort of correlation seemed to work particularly well, reported that the good results were due, not to the plan as such, but to the consummate skill of the teachers, who in his opinion could have made almost any plan a success. Mr. F. T. Jones of University School, Cleveland, Ohio, expressed himself similarly a few weeks ago. The most significant utterance on this point is Professor G. W. Myers' report in The School Review, October, I907, to which I can only refer. Althotigh these experiments have not produced the results expected of them, they have by no means been useless. They have shown the teachers of mathematics their limitations, have awakened an interest in applied mathematics, and have greatly enriched our problem literature. More promising than these forms of external correlation have been certain more recent attempts to secure a closer union of the various branches of pure mathematics. These efforts are still confined to a few high schools and colleges. So far as it is safe to draw conclusions from a very limited experience, the indications are that here lies our only hope of overcoming the compartment system.

The Future Course. I trust that I have now established the necessity and the actuality of a reform movement in the teaching of mathentatics. We must consider what will be the probable outcome of the struggle, as far as geometry is concerned. It is safe to say that whatever changes occur, they will all be in the direction of greater interest, more applied work, and fewer technicalities. It is also certain that the teacher of geometry must revise his aim, readjust the subject matter, and modennize his methods. 
Aim. The one-sided theory of mental discipline in the elementary course must go. The over-insistence on discipline for its own sake has done incalculable harm to the interests of mathematics. It is well that we are beginning to realize this. The report of the New England Association mentioned above contains this lament: "The general impression is abroad that mathematics is of little practical value, and the result has been its neglect and the consequent loss of mathematical power on the part of the pupils." Ours is not the calm repose of the Greek philosopher. Our civilization craves action, and a subject that loses contact with life is doomed.

It is a mistake to suppose that the high school can distinguish sharply between rational geometry and intuitive geometry. Their separation at this stage of the pupil's development is neither possible nor desirable, as Professor John Dewey has pointed out. In fact, what is rational geometry? The content of this conception is far from absolute. Says Professor Moore, "The teacher is teaching the subject for the benefit of the students, and it must be admitted that beginners in the study of demonstrative geometry cannot appreciate the very delicate considerations involved in the thoroughly abstract science. Indeed, one may conjecture that, had it not been for the brilliant success of Euclid in his effort to organize into a formally deductive system the geometric treasures of his times, the advent of the reign of science in the modern sense might not have been so long deferred. Shall we then hold that in the schools the teaching of demonstrative geometry should be reformed in such a way as to take account of all the wonderful discoveries which have been made-many even recently - in the domain of abstract geometry? *** To make reforms of this kind, would it not be to repeat more gloriously the error of those followers of Euclid who fixed his 'Elements' as a text-book for elementary instruction in geometry over two thousand years ago?" Let us be perfectly honest about this matter. Let us give up that meaningless pretense of teaching rigorous geometry to boys and girls of fourteen or fifteen.

Subject Matter. Is it not true that we are trying to crowd into a single year more material than the young student can possibly absorb? Think of the many definitions, the I60 propositions, the numerous corollaries and originals called for by the usual course. We can secure a mechanical repetition of these 
things, but do they become part of the pupil's mental armature? Should we not eliminate all that is not absolutely essential?

I know of no better criterion for this process than Prof. Klein's definition of elementary mathematics: "In all domains of mathematics those parts are to be called elementary which can be understood by a pupil of average ability without long continued special study."

In the light of this eminently sensible definition, advanced by one of the greatest of living mathematicians, we can afford to omit those things which experience has proved to be of little or no value. There is a growing conviction that to this class of material belongs the whole subject of limits and incommensurables. Many secondary teachers, both here and abroad, have iong been of this opinion. For information on this point, I may refer to the reports of the New York High School Teachers' Association, of the New England Association, and the Centra1 Association. It is a great pleasure to note that even the colleges are adopting this view. In a paper published in School ScIence and Mathematics, Prof. H. E. Hawkes of Yale University says: "During ten years' experience in teaching geometry to students who have been in general carefully prepared by the best teachers, I do not believe I have met a dozen who understood the theory of limits. This is not the fault of the students nor of the teachers, nor entirely of the text-books. The difficulty lies in the fact that we are trying to do something that cannot be done. $* * *$ From every point of view that $I$ am able to take, the theory of limits in elementary teaching seems a failure. If both secondary and college teachers suddenly discover that they agree on this point, the rest is simple." Professor G. A. Miller writes: "It has become the fashion of textbook writers to call especial attention to the rigor of their presentations. Fortunately these claims are generally unsubstantiated. There are few things that would give more definite proof of the perfect unsuitableness of an elementary text-book than the fact that every step in the presentation was rigorous."

Applications. The time gained by such omissions could be devoted to the more significant topics, and would enable us to introduce at least a few interesting and valuable applications. The young student should not be expected merely to review formulas and recite theorems discovered ages ago. He has a perfect right to ask what it is all for. Fortunately, the geom- 
etry teacher, if he will take the necessary pains, need not fear this inquiry. The desideratum seems to be such a judicious mixture of theory and practice that complete oblivion will settle on the definition according to which "mathematics is the science in which we do not know what we are talking about and do not care whether what we say about it is true."

A National Syllabus. Now I grant that the elimination of non-essentials is a serious matter, if left entirely to the judgment of the individual teacher. Each teacher is more or less of a hobbyist. I therefore suggest that the various provisional syllabi now at our disposal be submitted to a new committee of ten which shall work out a national geometry syllabus. If compiled with the greatest care by representative men, men in close touch with the colleges and the secondary schools, it should exert the same unifying influence that has characterized the publications of former committees of the National Education Association. This national syllabus should be revised periodically, possibly every ten years. It should contain a carefully graded list of theorems. It should also give a discussion of disputed definitions, terms and symbols, and should offer advice as to methods of procedure.

Methods. This brings me to my last topic. More seens to have been written in the past five years on the pedagogy of mathematics, than during the preceding five decades: This is very reassuring. When many prominent mathematicians can devote so much of their energy to the interests of elementary mathematics, better times are surely coming. It is encouraging that we are gradually seeking emancipation from text-books, that the teacher really teaches. The genetic method and the laboratory mode are receiving their due amount of attention. There is an attempt to make the pupil a discoverer, to replace the receptive attitude by a creative spirit. We are securing a better balance between oral and written recitation. Text-books, too, are improving in arrangement and quality of material. In short. there is progress all along the line.

Conclusion. In conclusion I would say that the present situation more than ever before demands a real teacher, a teacher of broad scientific and pedagogic attainments, who, in spite of many unavoidable disappointments, knows how to preserve his optimism. Never in the history of the world have the opportunities for sound training been greater, never has the unique 
importance of mathematics been more generally recognized, nor has there been more mutual sympathy and coöperation. Many years ago an ardent admirer of our noble science, a romantic poet now almost forgotten, wrote these admonishing and inspiring words: "The true mathematician is an enthusiast, per. se. Without enthusiasm, no mathematics. The life of the gods is mathematics. All divine messengers must be mathematicians."

\section{ROCK CITY.}

\section{By William B. Kinnear, \\ Minneapolis, Kansas.}

In Ottawa County, Kansas, three miles southwest from Minneapolis, the county seat, there is an interesting phenomenon popularly known in the vicinity as "Rock City." The "city" consists of numerous rocks, mostly spherical in form, varying in size from twelve feet in diameter down to three feet. There are two groups, one embracing most of the larger and more perfectly spherical specimens, the other including, for the most part, smaller rocks with greater departures from prevailing type. The latter group is a few yards east of the other and the rocks are less numerous as well as smaller. The rocks are situated about halfway up the slope to the upland west of the Solomon

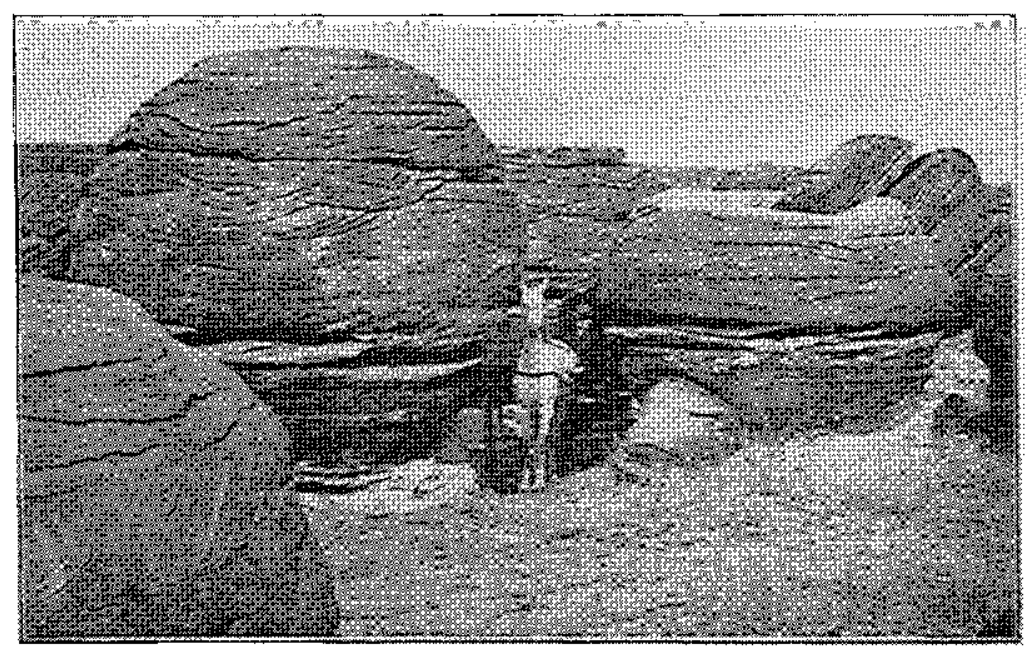

